\title{
Proceeding
}

8th INSHS International Christmas Sport Scientific Conference, 5-7 December 2013. International Network of Sport and Health

Science. Szombathely, Hungary

\section{Personality characteristics and its effect on performance in the race BMX}

\author{
SYLVA HŘEBIČKOVÁ , VIKTOR PACHOLÍK, JAN MACH, ROMANA LABOUNKOVÁ, PROGRAMBAN \\ NEM SZERPEL A NEVE \\ ${ }^{1}$ Faculty of Sport Studies, Masaryk University, Kamenice 753/5, 62500, Brno, Czech Republic
}

\begin{abstract}
Hřebíčková, S., Pacholík, V. \& Mach, J. (2014). Personality characteristics and its effect on performance in the race BMX. J. Hum. Sport Exerc., 9(Proc1), pp.S245-S248. The aim of this study was to describe personality characteristics of top athletes -10 elite bicross (BMX) racers (18+ years), both men and women. For our research we used SPARO test - monitoring of basal psychical autoregulation of personality, which was evaluated with t-test. Particular segments were compared with population and with top athletes of different sports. BMX racers had significantly higher $(p<0.05)$ intensity of autostimulation, airiness (-5.92 \pm 2.54$)$, searching for emotional experiences (3.4 \pm 2.35$)$ and higher willingness to risk $(6,54 \pm 2,37)$. Simultaneously it confirmed higher anxiety $(3.35 \pm 3,2.1)$, need of independence $(3,73 \pm 2.00)$ and dominant need of experiential attitude $(-2,55 \pm 2,38)$. Results show characteristics of BMX racers, which correspond with characteristic of this cycling discipline, and also show personality attributes which are important for success in this sport. Key words: PSYCHOLOGY, BICROSS, PERSONALITY CHARACTERISTIC.
\end{abstract}

Corresponding author. Faculty of Sport Studies, Masaryk University, Kamenice 753/5, 62500, Brno, Czech Republic.

E-mail: hrebickova@fsps.muni.cz

8th INSHS International Christmas Sport Scientific Conference, 5-7 December 2013. International Network of Sport and Health Science. Szombathely, Hungary.

JOURNAL OF HUMAN SPORT \& EXERCISE ISSN 1988-5202

(c) Faculty of Education. University of Alicante

doi:10.14198/jhse.2014.9.Proc1.05 


\section{INTRODUCTION}

BMX is an Olympic sport which consists of several repetitive rounds in one day (Mateo, 2012). Athletes ride a track which is different at every destination. Even a same track changes due to different weather conditons. Just in Supercross races there is a standardized size of the starting hill (Mateo, 2012). The track consists of straights - usually four, jumps and turns. The race last two days. Qualification is at first day and every athlere ride full measured lap. Race at second day includes 3 qualifying rounds, quarterfinal, semifinal and final. Each lap lasts 30 to 40 seconds, contains approximately 6 sprints lasting 1-3 seconds (Tanner, 2013) (Louis, 2012). 8 riders are performing at every moto, just four of them qualify for the next round. According to previous performance riders are seeded and they pick their starting line in following laps. That is the reason why every single lap is important and riders have to retain their short-term and long-term concetration especially at critical moments and pre-start conditions.

\section{METHODS}

\section{Participants}

The aim of this study was to describe personality characteristics of top athletes - 10 elite bicross (BMX) racers (18+ years), both men (8) and women (2) (See Table 1).

\section{Measures}

For our research we used SPARO test - monitoring of basal psychical autoregulation of personality (Mikšík, 2004), which was evaluated with t-test.

SPARO affects the basic components of the basal psychic of integration:

$\mathrm{KO}=$ cognitive variability

$E M=$ emotional variability

$\mathrm{RE}=$ control variability

$A D=$ adjustment variability

Basal range of variability:

$\mathrm{PV}=$ general level of psychological (internal) arousal, spontaneity, $\mathrm{MH}=$ motor (or external) momentum.

Table 1. Age of participants

\begin{tabular}{lll}
\hline \hline BMX riders & age (years) & SD \\
\hline men $(\mathrm{n}=8)$ & 22.88 & \pm 5.72 \\
women $(\mathrm{n}=2)$ & 26.5 & \pm 3.54 \\
all $(\mathrm{n}=10)$ & 23.6 & \pm 5.40 \\
\hline
\end{tabular}

\section{Procedures}

The questionnaire was completed by respondents in a quiet environment without distractions, without shortterm emotional strain. The questionnaire includes two types of criteria of credibility (or relative reliability) of the respondent's answers.

The first is the assessment of the relationships between scores on scales for prosecuting certain set of above features results in the scales specifically created. $U$ truthfully completed questionnaires range of OS, 
$\mathrm{OR}$ and $\mathrm{Ol}$ must possess the same nature deviations core values comparable population such as that resulting from variations in the resulting trend set of features into this dimension of entering. As a second criterion used is the so-called $\mathrm{K}$ - score extreme statements, which verifies the importance of disparities in relations between the above scales in the traditional way - by the "lie - score", if these disparities do not act, reveal significant saturation range $\mathrm{K}$ (extreme scores) "problem" with the outcome of the range EX (extremity) corresponding ("extreme") of an individual.

Analysis

Particular segments were compared with population and with top athletes of different sports. Level of significance was $(p<0.05 * ; p<0.01 * *)$. SPARO is the basic diagnostic tool battery DIAROS. It is a revised and further developed variant of the developmental series SPIDO - IHAVES - VAROS - Ihara - IHATRANS.

\section{RESULTS}

We compared studied group of probands - men and women (BMX athletes, $n=10)$ with standards for population. In general personality characteristics results indicate type B3 - excitable, quick-tempered type, which connect higher emotional excitability $(E M+)$ with spontaneous situation reactivity $(R E+)$. Results also indicates inconstancy of adjustability (AD-) in connection with cognitive variability (KO+). It is typical for personality of this type to be more sensitive in high emotional conditions, what manifests in high psychical lability and spontaneous, less controled reactions (Figure.1).

We can also identify some characteristics, which are specific for this group of athletes: Psychical lability (LS-) is a dominant attribute. It manifests in more impulsive reactions or quick changes of mood. Exciting enviroment which promises intensive emotional experiences (IP+) is their priority. Athletes prefer more risky activities and decisions, but results of these activities are not as important as their process and experience. It has an effect on higher aspiration but lower anticipation (AC-) of results of their decisions and tendency to higher willingness to risk (TN+) and start activities with very low possibility to succes or with risk of lost. Despite mentioned characteristics probands show higher degree of anxiety (UZ+). This anxiety states can disrupt autoregulation mechanisms, understanding and evaluation of certain situations and can lead to choice of inefficient forms of behaviour in that situation. Results show a need of making and retaining of social relations $(\mathrm{KT}+)$, searching of society and need of sharing experiences with other people. There is an evident need of independence ( $\mathrm{NE}+$ ) and unwillingness to agree with opinions of other people. Results also indicate airiness (LO-) and lower responsibility to standards, rules, tasks, people etc. It relates with higher recklessness and exuberance.

\section{DISCUSSION}

Due to the nature of sport results correspond with the demands that are placed on the rider in BMX. Increased risk appetite and risk in decision-making related to the need to establish themselves among the seven rivals in a very short time (usually the first section of track) and on the track, which offers a lot of technical passages. Higher level of aspiration and a higher rate of anxiety correspond with the need to process, concentrating on several consecutive races. Given the results would be good comparsion to similar disciplines of cycling, that take place in different contexts, such as track cycling - sprints. To confirm the character traits and then completely different cycling disciplines - road biking or Mountainbiking. 


\section{CONCLUSION}

BMX racers had significantly higher $(p<0.05)$ intensity of autostimulation, airiness $(-5.92 \pm 2.54)$, searching for emotional experiences $(3.4 \pm 2.35)$ and higher willingness to risk $(6,54 \pm 2,37)$. Simultaneously it confirmed higher anxiety $(3.35 \pm 3,2.1)$, need of independence $(3,73 \pm 2.00)$ and dominant need of experiential attitude $(-2,55 \pm 2,38)$. Results show characteristics of BMX racers, which correspond with characteristic of this cycling discipline, and also show personality attributes which are important for success in this sport.

This research was funded within the specific research project "The concentration of attention as one of the prerequisites for successful performance in cycling" „C. MUNIA/A/0829/2012 ID 23564“.

\section{REFERENCES}

1. Louis, J., Billaut, F., Bernad, T., Vettoretti, F., Hausswirth, C. \& Brisswalter, J. (2012). Physiological demands of a simulated BMX competition. Int J Sports Med, 10, pp.0032-1327657.

2. Mateo, M., Blasco-Lafarga, C., Martínez-Navarro, I., Guzmán, J.F. \& Zabala, M. (2012). Heart rate variability and pre-competitive anxiety in BMX discipline. European journal of applied physiology, 112(1), pp.113-123.

3. Mateo, M., Blasco-Lafarga, C., Doran, D., Romero-Rodríguez, R.C. \& Zabala, M. (2012). Notational analysis of European, World, and Olympic BMX cycling races. Int J Sports Med, 11, pp.502-509.

4. Mikšík, O. (2004). Dotazník SPARO: Př́ručka. Brno: Psychodiagnostika s.r.o.

5. Tanner, R. \& Gore, C. (2013). Physiological Tests for Elite Athletes, 2E. Human Kinetics. 